\title{
PENGARUH DEBT TO EQUITY RATIO, CURRENT RATIO DAN NET PROFIT MARGIN TERHADAP PERTUMBUHAN LABA \\ (Studi pada Perusahaan yang terdaftar di Indeks LQ-45 Bursa Efek Indonesia)
}

\author{
Nur Amalina, Adi Rizfal Efriadi \\ Institut Teknologi dan Bisnis Ahmad Dahlan \\ Amel1002.ya@gmail.com
}

\begin{abstract}
This study aims to determine the effect of debt to equity ratio, current ratio and net profit margin on company income growth. This type of research is quantitative with a descriptive approach. The population in this study is the LQ45 non-financial company listed on the Indonesia Stock Exchange in 2016-2019. The sample selection technique is using purposive sampling. The type of data used is student data. The data analysis technique in this study used multiple linear regression analysis. The results of this study indicated that debt to equity ratio, current ratio, net profit margin have a significant effect on company income growth.
\end{abstract}

Keywords: Debt to equity ratio, current ratio, net profit margin, income growth

\begin{abstract}
ABSTRAK
Penelitian ini bertujuan untuk mengetahui pengaruh debt to equity ratio, current ratio dan net profit margin terhadap pertumbuhan laba perusahaan. Jenis Penelitian ini adalah kuantitatif dengan pendekatan deskriptif. Populasi dalam penelitian ini adalah perusahaan perdagangan dan manufaktur LQ-45 yang terdaftar di Bursa Efek Indonesia tahun 2016-2019. Teknik pemilihan sampel yaitu menggunakan purposive sampling. Jenis data yang digunakan yaitu data sekuder. Teknik analisis data dalam penelitian ini menggunakan analisis regresi linier berganda. Hasil penelitian menunjukkan bahwa debt to equity ratio, current ratio, net profit margin berpengaruh positif terhadap pertumbuhan laba perusahaan.
\end{abstract}

Kata kunci: Debt to equity ratio, current ratio, net profit margin, pertumbuhan laba

\section{PENDAHULUAN}

Kompetisi usaha pada saat ini sangatlah cepat begitupun di Indonesia semakin meningkat cepat dan kondisi perekonomi yang dinamis membuat perusahaan menjadi lebih profesional, dengan begitu persaingan antar perusahaan dapat dirasakan sangat kompetitif dan kompleks sehingga berdampak kuat bagi perusahaan. Karena itu timbulnya persaingan yang begitu ketat di dunia usaha sehingga perusahaan dituntut agar dapat meningkatkan usaha perusahaan dengan sebaik dan semaksimal mungkin agar dapat mencapai satu tujuan yang layak dan salah satu caranya yaitu mendaftarkan perusahaanya pada Bursa Efek Indonesia (BEI) dengan begitu perusahaan yang terdaftar di BEI semakin meningkat yang membuat persaingan antar Perusahaan semakin meningkat. 
Setiap perusahaan mempunyai tujuan yang pada umumnya adalah untuk memperoleh peningkatan laba atau profit. Prediksi terhadap pertumbuhan laba berguna untuk investor yang ingin menginvestasikan modal pada perusahaan dan manajemen perusahaan untuk mengevaluasi kebijakan yang telah mereka tetapkan. Bagi para pengguna laporan keuangan itu sangat penting agar dapat mengetahui tingkat pertumbuhan laba karena berpengaruh terhadap keputusan investasi dan investor yang ingin melakukan investasi kedalam perusahaan.

\section{KERANGKA TEORITIS}

\section{Analisis laporan keuangan}

Analisis laporan keuangan adalah untuk melihat status keuangan perusahaan dan analisis kinerja keberhasilan perusahaan pada masa sebelumnya dan pada saat ini, dan untuk memprediksi di masa yang akan datang. Menurut Sirait (2017), analisis laporan keuangan adalah penguraian materi laporan keuangan kepada hal-hal yang penting untuk mudah dimengerti makna yang tersirat sehingga dapat digunakan untuk pengambilan keputusan tertentu". Menurut Harahap (2015) rasio keuangan merupakan angka yang didapatkan dari hasil perbandingan dari suatu pos laporan keuangan dengan pos lain yang memilki hubungan relevan dan signifikan. Rasio yang dipakai dalam penelitian ini, antara lain: (1) Debt to Equity Ratio (DER), DER adalah salah satu dari beberapa rasio yang dipakai untuk menilai hutang dan ekuitas; (2) Current Ratio (CR), CR merupakan rasio likuditas yang menjelaskan bahwa perusahaan mampu memenuhi kewajiban yang harus dilakukan oleh alat likuidnya dengan cepat; (3) Net Profit Margin (NPM), NPM yaitu rasio yang dipakai dalam mengukur kemampuan perusahaan dalam menghasilkan laba bersih setiap penjualan, dihitung dengan membagikan laba bersih terhadap penjualan; dan (4) Pertumbuhan Laba, menurut Estininghadi (2018) pertumbuhan laba merupakan peningkatan atau penurunan laba yang didapat dibandingkan dengan tahun sebelumnya. Dengan meningkat laba hal ini menandakan bahwa perusahaan memiliki profil kinerja yang baik sehingga menarik minat investor untuk berinvestasi. Untuk menghitung dapatdirumuskan sebagai berikut:

$$
P L=\frac{\text { Laba bersih tahun ini }- \text { Laba bersih tahun lalu }}{\text { Laba bersih tahun lalu }}
$$


Kerangka konseptual penelitian ini, disajikan pada Gambar 1.

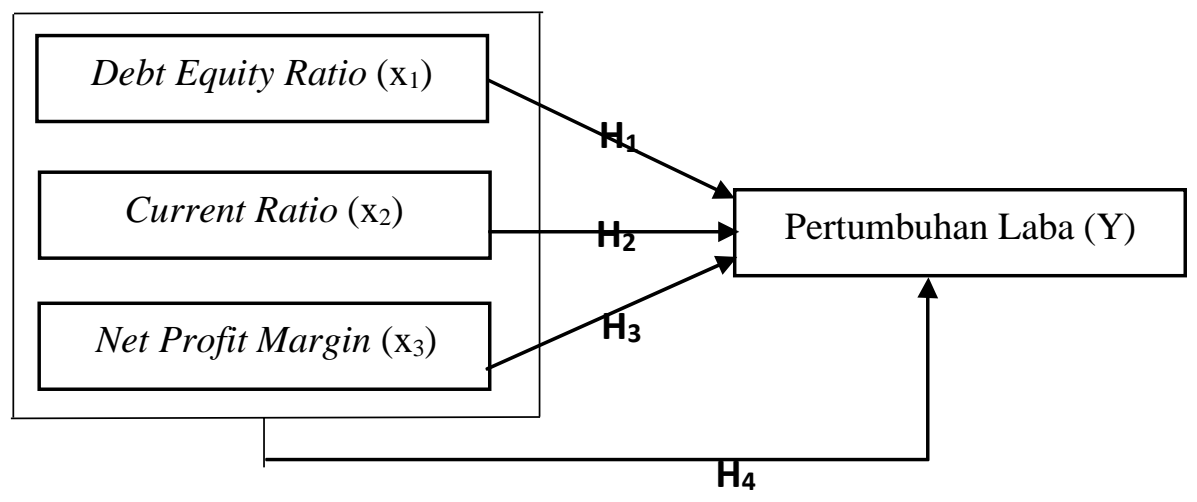

Gambar 1. Kerangka Penelitian

Berdasarkan penjelasan pada pembahasan dari landasan teori penelitian sebelumnya, terdapat beberapa hipotesis yang dapat dirangkum yang dapat digunakan sebagai acuan dalam penyususan hipotesis. Hipotesis pada penelitian ini sebagai berikut:

$\mathbf{H}_{1}$ : Debt to equity ratio berpengaruh terhadap pertumbuhan laba

H2: Current ratio berpengaruh terhadap pertumbuhan laba

H3: Net profit margin berpengaruh terhadap pertumbuhan laba

H4: Debt to equity ratio, current ratio dan net profit margin terhadap pertumbuhan laba

\section{METODE PENELITIAN}

\section{Desain Penelitian}

Desain penelitian merupakan rencana yang dibuat peneliti sebagai perancangan kegiatan yang akan dilakukan dan tipe penelitian yang dipakai tergantung pada jenis masalah. Menurut Sugiyono (2017) "Metode penelitian adalah cara ilmiah agar memperoleh data dengan maksud serta tujuan sendiri”. Penelitian yang digunakan yaitu penelitian kuantitatif Jenis data yang dipakai yaitu data sekunder yang merupakan data kuantitatif yang didapat dari website resmi Bursa Efek Indonesia yaitu www.idx.co.id dan data yang dipakai yaitu laporan keuangan tahunan perusahaan yang terdaftar dalam indeks LQ-45 Tahun 2016-2019.

Metode penelitian menggunakan metode deskriptif kausal. Deskriptif mempunyai tujuan mendeskripsikan sifat atau karakteristik suatu peristiwa tertentu. Desain kausal ini yaitu untuk menganalisis hubungan antar satu variabel dengan varibael lainya atau seperti apa suatu variabel mempengaruhi variabel lainya. Desain kausal dipakai untuk menjelasankan hubungan antar variabel melalui uji hipotesis, desain kausal mempelajari secara dalam hubungan sebab akibat sekaligus untuk menemukan hubungan antar variabel dan masalah 
tujuan penelitian. Penelitian ini menggunakan variabel-variabel yaitudebt to equity ratio (DER), Current Ratio (CR), Net Profit Margin (NPM) dan pertumbuhan laba.

Teknik pengumpulan data yang digunakan yaitu dokumentasi. Data yang dipakai pada penelitian ini yaitu data sekunder. Populasi pada penelitian yang menjadi populasi yaitu perusahaan yang berada di indeks LQ-45 di BEI tahun 2016-2019 secara berturut-turut. Tidak semua perusahaan dalam populasi dapat menjadi sampel penelitian karena tidak semua perusahaan secara konsisten tetap bertahan di indeks LQ-45 selama periode 2016-2019 secara berturut-turut. Untuk itu perlu dilakukan uji kriteria sampel untuk menentukan perusahaan yang memenuhi kriteria dan dapat dijadikan sampel. Dalam mengambil sampel pada penelitian ini memakai teknik purposive sampling. yaitu teknik yang dianggap sebagai teknik pengambilan sampel dengan pertimbangan tertentu yang cocok untuk penelitian kuantitatif.

Teknik analisis data yaitu teknik yang dipakai dalam mengolah data yang didapat sehingga data itu dapat memberikan keterangan sehingga dapat dipahami, jelas dan teliti. Teknik yang dipakai di penelitian ini adalah analisis regresi linier berganda. Analisis ini dipakai untuk menguji seberapa besar hubungan antar dua variabel yang menunjukkan bahwa variabel dependen mampu bergantung pada lebih dari satu variabel independen (Ghozali, 2018). Hasil dari pengujian analisis regresi linier berganda berupa penolakan atau penerimaan dari hipotesis penelitian. Adapun persamaan regresi yang digunakan pada penelitian ini adalah:

$$
\mathrm{Y}=\alpha+\beta 1 \mathrm{X} 1+\beta 2 \mathrm{X} 2+\beta 3 \mathrm{X} 3+\mathrm{e}
$$

Keterangan:

$\mathrm{Y} \quad=$ Pertumbuhan Laba

$\alpha \quad=$ Konstanta

$\beta 1, \beta 2, \beta 3=$ Koefisien regresi masing-masing variabel independen

X1 = Debt to Equity Ratio

X2 = Current RatioX3 = Net Profit Margin

e $\quad=$ Error/residual

Uji hipotesis dapat digunakan untuk mengecek atau menguji apa koefisien regresi yang diperoleh signifikan. Uji $\mathrm{t}$ dan $\mathrm{F}$ dapat menyelesaikan dua jenis koefisien regresi. RSquare memiliki tujuan untuk mengukur seberapa besar kemampuan model untuk mengartikan variabel dependen (Ghozali, 2018). Koefisien determinasi berada di antara nol dan satu. Nilai R Square yang kecil menunjukkan bahwa kemampuan variabel independen 
untuk mengartikan variabel dependen sangat terbatas. Jika nilai R-Square mendekati 1 , artinya variabel independen menjelaskan hampir secara menyeluruh informasi yangdibutuhkan dalam memprediksi perubahan variabel dependen.

Menurut Ghozali (2018) "Uji statistik t merupakan uji yang dilakukan untuk melihat seberapa besar pengaruh variabel independen secara individual terhadap variabel dependen. Pengujian statistik $\mathrm{t}(\mathrm{t}-\mathrm{test})$ dilakukan menggunakan significance level $0,05(\alpha=5 \%)$. Menerima atau menolak hipotesis penelitian menggunakan kriteria antara lain: Jika nilai signifikan yaitu $>0,05$ berarti hipotesis tersebut ditolak. Artinya bahwa secara parsial variabel independen tersebut tidak mempunyai pengaruh terhadap variabel dependen. independen tersebut memiliki pengaruh terhadap variabel dependen.

Menurut Ghozali (2018:179) uji statistik F adalah uji yang digunakan untuk melihat adakah pengaruh antara variabel independen dengan variabel dependen secara simultan. Berikut ini kriteria pengambilan keputusan uji statistik F yaitu :

1. Bila nilai $\mathrm{F}$ dihitung yaitu $>$ nilai $\mathrm{F}$ tabel berarti seluruh variabel independen secara bersamaan mempengaruhi variabel dependen.

2. Bila nilai $\mathrm{F}$ dihitung yaitu $\leq$ nilai $\mathrm{F}$ tabel berarti semua variabel independen secara bersamaan tidak mempengaruhi variabel dependen.

Menurut Ghozali (2018), hasil uji statistik F dapat dilihat berdasarkan signifikansi. Apabila nilai signifikansi $<0,05$ artinya semua variabel independen secara bersama-sama (simultan) berpengaruh terhadap variabel dependen.

\section{ANALISIS DAN PEMBAHASAN}

Sampel penelitian ini adalah perusahaan yang terdaftar di indeks LQ-45 di BEI dari tahun 2016-2019. Perusahaan-perusahaan tersebut memiliki likuiditas yang tinggi dan nilai pasar yang besar, serta memiliki fundamental perusahaan yangbaik. Dalam penelitian ini digunakan metode purposive sampling

Analisis statistik deskriptif dipakai dalam menjelaskan data variabel penelitian. Di Dalam penelitian ini dapat diambil gambaran tentang variabel penelitian mengenai nilai minimum, maksimum, rata-rata (mean) dan standar deviasi. Hasil statistik deskriptif disajikan pada Tabel 1. 
Tabel 1. Hasil Statistik Deskriptif

\begin{tabular}{lcccc}
\hline \multicolumn{1}{c}{ Variabel } & Min & Max & Mean & Std. Deviation \\
\hline DER & 0,15 & 3,31 & 0,89 & 0,78 \\
CR & 31,14 & 527,23 & 210,34 & 128,35 \\
NPM & 0,71 & 33,40 & 13,71 & 7,54 \\
PertumbuhanLaba & 1,02 & 874,00 & 54,74 & 168,50 \\
\hline Sumber: Data Sekunder - hasil olah data SPSS & & &
\end{tabular}

Sebelum analisis regresi berganda, penelitian harus lolos syarat uji asumsi klasik. Syarat yang harus dipenuhi dalam uji asumsi klasik yaitu uji normalitas, uji multikolinearitas, uji heteroskedastisitas, dan uji autokorelasi. Hasil dari uji asumsi klasik disajikan pada Tabel 2 .

Tabel 2. Hasil Uji Normalitas

One-Sample Kolmogorov-Smirnov Test

\begin{tabular}{|ll|r|}
\hline & & $\begin{array}{r}\text { Unstandardiz } \\
\text { ed Residual }\end{array}$ \\
\hline $\mathrm{N}$ & Mean & 46 \\
Normal Parameters & a,b & $-2,4269620$ \\
Most Extreme Differences & Absolute & 4,48369751 \\
& Positive &, 099 \\
& Negative &, 099 \\
Test Statistic & &,- 070 \\
Asymp. Sig. (2-tailed) & &, 099 \\
\hline
\end{tabular}

Sumber: Data diolah IBM SPSS 22, 2021

Berdasarkan hasil dari tabel 2, nilai Kolmogrov-Smirnov adalah 0,99 dan signifikan pada 0,200. Nilai Asym. Sig. (2-tailed) lebih besar dari nilai signifikan sebesar 0,200>0,05 maka dapat disimpulkan data tersebut berdistribusi normal atau telah memenuhi uji asumsi klasik

Tabel 3. Hasil Uji Multikolinieritas

Coefficients $^{a}$

\begin{tabular}{|c|c|c|c|c|c|c|c|c|}
\hline \multirow[b]{2}{*}{ Mod } & & \multicolumn{2}{|c|}{ Unstandardized Coefficients } & \multirow{2}{*}{$\begin{array}{c}\text { Standardized } \\
\text { Coefficients } \\
\text { Beta }\end{array}$} & \multirow[b]{2}{*}{$t$} & \multirow[b]{2}{*}{ Sig. } & \multicolumn{2}{|c|}{ Collinearity Statistics } \\
\hline & & $B$ & Std. Error & & & & Tolerance & VIF \\
\hline \multirow[t]{4}{*}{1} & (Constant) &,- 037 & 3,815 & &,- 010 &, 992 & & \\
\hline & DER (X1) & 5,291 & 3,299 &, 404 & 1,604 &, 116 &, 344 & 2,906 \\
\hline & $\mathrm{CR}(\times 2)$ & 011 &, 008 &, 372 & 1,460 &, 152 &, 336 & 2,975 \\
\hline & NPM $(\times 3)$ &,- 081 & 084 &,- 153 &,- 968 & 339 & 878 & 1,139 \\
\hline
\end{tabular}

a. Dependent Variable: Pertumbuhan Laba $(\mathrm{Y})$

Sumber: Data diolah IBM SPSS 22, 2021

Berdasarkan Tabel 3 diketahui bahwa nilai VIF (variance inflation factor) debt to equity ratio $2,906<10$; current ratio yaitu sebesar 2,975 < 10; net profit margin sebesar 1,139 $<10$, artinya model regresi dapat dikatakan tidak mengalami masalah multikolinieritas. 


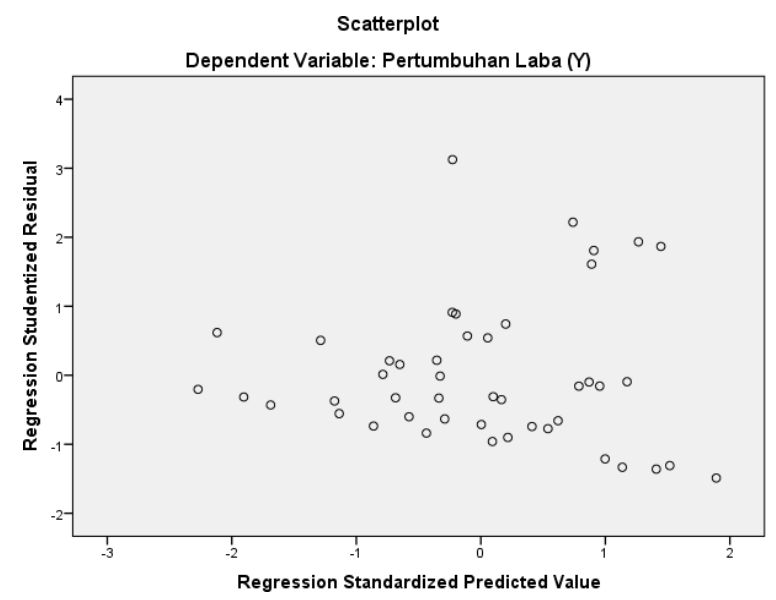

Gambar 1. Hasil Uji Heteroskedastisitas

Berdasarkan hasil dari Uji Heteroskedastisitas pada Gambar 1. diketahui bahwa penyebaran terjadi di atas dan di bawah angka 0 pada sumbu $\mathrm{Y}$ artinya adalah tidak adanya masalah heteroskedastisitas.

Tabel 4. Hasil Uji Regresi Berganda

\begin{tabular}{|c|c|c|c|c|c|c|}
\hline & & \multicolumn{5}{|c|}{ Coefficients $^{a}$} \\
\hline \multirow{2}{*}{\multicolumn{2}{|c|}{ Model }} & \multicolumn{2}{|c|}{ Unstandardized Coefficients } & \multirow{2}{*}{$\begin{array}{c}\begin{array}{c}\text { Standardized } \\
\text { Coefficients }\end{array} \\
\text { Beta } \\
\end{array}$} & \multirow[b]{2}{*}{$t$} & \multirow[b]{2}{*}{ Sig. } \\
\hline & & $\mathrm{B}$ & Std. Error & & & \\
\hline \multirow[t]{4}{*}{1} & (Constant) &,- 037 & 3,815 & &,- 010 &, 992 \\
\hline & DER (X1) & 5,291 & 3,299 & 404 & 1,604 &, 116 \\
\hline & $\mathrm{CR}(\times 2)$ & 011 &, 008 & 372 & 1,460 & 152 \\
\hline & NPM $(\times 3)$ &,- 081 &, 084 &,- 153 &,- 968 &, 339 \\
\hline
\end{tabular}

a. Dependent Variable: Pertumbuhan Laba $(Y)$

Sumber: Data diolah IBM SPSS 22, 2021

Berdasarkan tabel 4 maka di dapatkan persamaan regresi yang dipakai di penelitian ini sebagai berikut:

\section{Pertubuhan Laba $=-0,037+5,291$ DER + 0,011 CR + -0,081NPM + e}

Berdasarkan persamaan dengan model regresi linier berganda tersebut, maka dapat dijelaskan secara rinci. Constant mempunyai nilai -0,037 yaitu jika nilai current ratio, debt to equity ratiodan net profit margin bernilai nol, dapat dikatakan nilai pertumbuhan laba yaitu 0,037. Debt to equity ratio dalam model digambarkan berkorelasi positif dengan nilai 5,291 yang berarti jika debt-to-equity ratio meningkat maka pertumbuhan laba akan meningkat sebesar 5,291 jika estimasi current ratio dan net profit margin tetap tidak berubah. Current ratio dalam model ini digambarkan sebagai korelasi positif dengan nilai 0,011 yang berarti jika rasio lancar meningkat maka pertumbuhan laba akan meningkat sebesar 0,011 jika 
estimasi debt to equity ratio dan net prfoit margin bernilai konstan. Net profit margin dalam model ini diartikan sebagai hubungan negatif dengan nilai -0,081 yang artinya jika tingkat laba bersih meningkat maka pertumbuhan laba akan turun sebesar -0,081 jika estimasi current ratio dan debt-to-equity ratio tetap tidak berubah.

Tabel 5. Hasil Uji Koefisien Determinasi

\begin{tabular}{|c|c|c|c|c|c|}
\hline \multicolumn{6}{|c|}{ Model Summary ${ }^{b}$} \\
\hline Model & $\mathrm{R}$ & R Square & $\begin{array}{c}\text { Adjusted R } \\
\text { Square }\end{array}$ & $\begin{array}{l}\text { Std. Error of } \\
\text { the Estimate }\end{array}$ & $\begin{array}{l}\text { Durbin- } \\
\text { Watson }\end{array}$ \\
\hline 1 & $285^{\mathrm{a}}$ &, 081 &, 016 & 3,79304 & 1,129 \\
\hline \multicolumn{6}{|c|}{ a. Predictors: (Constant), NPM (X3), DER (X1), CR (X2) } \\
\hline \multicolumn{6}{|c|}{ b. Dependent Variable: Pertumbuhan Laba (Y) } \\
\hline
\end{tabular}

Koefisien determinasi $\left(\mathrm{R}^{2}\right)$ adalah pengukur kontribusi antara variabel bebas terhadap variabel tergantungnya. Semakin meningkat koefisien determinasi, maka semakin meningkat kemampuan variabel bebas dalam menarangkan variasi perubahan pada variabel tergantungnya. Berdasarkan tabel model summary didapat nilai Adjusted $R$ Square sebesar 0,16. Hal ini berarti sebsar $16 \%$ variabel manajemen laba dapat dijelaskan dan sisanya sebesar $84 \%$ dijelaskan oleh variabel lain diluar model penelitian ini.

Tabel 6. Hasil Uji t (Uji Parsial)

\begin{tabular}{|c|c|c|c|c|c|c|}
\hline & & \multicolumn{5}{|c|}{ Coefficients $^{a}$} \\
\hline \multirow{2}{*}{\multicolumn{2}{|c|}{ Model }} & \multicolumn{2}{|c|}{ Unstandardized Coefficients } & \multirow{2}{*}{$\begin{array}{c}\text { Standardized } \\
\text { Coefficients } \\
\text { Beta }\end{array}$} & \multirow[b]{2}{*}{$t$} & \multirow[b]{2}{*}{ Sig. } \\
\hline & & $\mathrm{B}$ & Std. Error & & & \\
\hline \multirow[t]{4}{*}{1} & (Constant) &,- 037 & 3,815 & &,- 010 & 992 \\
\hline & DER $(\times 1)$ & 5,291 & 3,299 & ,404 & 1,604 & 116 \\
\hline & $\mathrm{CR}(\times 2)$ & 011 &, 008 &, 372 & 1,460 & 152 \\
\hline & NPM (X3) &,- 081 & 084 &,- 153 &,- 968 &, 339 \\
\hline
\end{tabular}

a. Dependent Variable: Pertumbuhan Laba $(Y)$

Sumber: Data diolah IBM SPSS 22, 2021

Berdasarkan hasil dari uji t pads tabel 6, maka dapat disimpulkan beberapa keputusan sebagai berikut:

1. Debt to equity ratio mempunyai nilai Sig. $t$ sebesar $0,116>0,05$ jadi dapat ditarik kesimpulan bahwa DER secara parsial berpengaruh positif terhadap pertumbuhan laba perusahaan.

2. Current ratio mempunyai nilai Sig. $t$ sebesar $0,152>0,05$. Oleh karena itu dapat disimpulkan bahwa CR secara parsial berpengaruh positif terhadap pertumbuhan laba.

3. Net profit margin mempunyai nilai Sig. $t$ sebesar $0,339>0,05$. Oleh karena itu dapat 
disimpulkan bahwa NPM secara parsial berpengaruh positif terhadap pertumbuhan laba.

Tabel 7. Hasil Uji F (Uji Simultan)

ANOVA $^{\text {a }}$

\begin{tabular}{|ll|r|r|r|r|r|}
\hline Model & & \multicolumn{1}{|c|}{$\begin{array}{c}\text { Sum of } \\
\text { Squares }\end{array}$} & \multicolumn{1}{c|}{ df } & Mean Square & F & Sig. \\
\hline 1 & Regression & 53,464 & 3 & 17,821 & 1,239 &, $308^{\text {b }}$ \\
& Residual & 604,260 & 42 & 14,387 & & \\
& Total & 657,725 & 45 & & & \\
\hline
\end{tabular}

Sumber: Data diolah IBM SPSS 22, 2021

Hasil uji statistik F dapat dilihat dari segi signifikansi. Jika nilai signifikansi lebih kecil dari 0,05, artinya semua variabel independen mempengaruhi variabel dependen secara bersamaan (simultan). Berdasarkan tabel ANNOA diatas menunjukkan bahwa hasil uji $\mathrm{F}$ signifikan bila 0,308> 0,05 yang menunjukkan signifikansi yaitu H0 diterima dan H1 ditolak. Artinya debt to equity ratio, current ratio dan net profit margin tidak akan terpengaruh pada saat yang bersamaan.

\section{KESIMPULAN}

Penelitian ini dilakukan untuk memperoleh bukti empiris mengenai adanya pengaruh debt to equity ratio, current ratio dan net profit margin terhadap pertumbuhan laba perusahaan. Pada penelitian ini disimpulkan bahwa secara parsial seluruh variabel berpengaruh terhadap pertumbuhan laba perusahaan hal ini dapat dirangkum sebagai berikut: Debt to equity ratio mempunyai nilai Sig. $t$ sebesar 0,116 $>0,05$. menjelaskan secara parsial berpengaruh positif terhadap pertumbuhan laba. Current ratio mempunyai nilai Sig. $t$ sebesar 0,152>0,05 secara parsial menjelaskan berpengaruh positif terhadap pertumbuhan laba. Net profit margin mempunyai nilai Sig. $t$ sebesar 0,339>0,05 menjelaskan secara parsial berpengaruh positif terhadap terhadap pertumbuhan laba. Debt to equity ratio, current ratio, net profit margin Berdasarkan tabel ANNOA menunjukkan bahwa hasil uji F signifikan bila 0,308>0,05 secara simultan berpengaruh terhadap pertumbuhan laba.

Dan berdasarkan hasil penelitian yang telah dilaksanakan maka penulis mengusulkan beberapa saran agar peneliti selanjutnya diharapkan memperluas sampel yang dipakai pada penelitian ini untuk penelitian selanjutnya, atau menjadi lebih komprehensif dalam penelitian selanjutnya.Untuk peneliti selajutnya diharapkan memperpanjang waktu penelitian pada peneliti berikutnya untuk membuat hasil statistik menjadi lebih baik. Serta, menggunakan objek dan waktu yang berbeda pada penelitian berikutnya agar meneukan fenomena baru. 


\section{DAFTAR PUSTAKA}

Estininghadi, S. 2018. Pengaruh current ratio (CR), debt to equity ratio (DER), total asset turn over (TATO) dan net profit margin (NPM) terhadap pertumbuhan labapada perusahaan property and estate yang terdaftar di Bursa Efek Indonesia.

Sirait, Pirmatya. 2017, Analisis Laporan Keuangan.Yogyakarta: Ekuilibria Harahap, S. S 2015, Analisis Kritis Atas Laporan Keuangan. Jakarta: PT. Raja Grafindo

Ghozali, Imam. 2018. Aplikasi Analisis Multivariate Dengan Program IBM SPSS 25 Edisi 9. Semarang: Badan Penerbit Universitas Diponegoro.

Juliandi, A., Irfan, I., \& Manarung, S. (2015). Metode Penelitian Bisnis : Konsep \& Aplikasi. Medan: Umsu Press.

Sunyoto, D. 2016, Metodologi Penelitian Akuntansi. Bandung: PT. Refika Aditama Sugiyono. 2017. Metode Penelitian Kuantitatif, Kualitatif, dan R\&D. Bandung: Alfabeta.

www.idx.co.id. Bursa Efek Indonesia, 2020 IDX LQ 45 February 2016 - July 2016, di akses 15 Februari 2020

www.idx.co.id. Bursa Efek Indonesia, 2020 IDX LQ 45 Agustus 2016 - January 2017, diakses 15 Februari 2020

www.idx.co.id. Bursa Efek Indonesia, 2020 IDX LQ 45 February 2017 - July 2017, di akses 15 Februari 2020

www.idx.co.id. Bursa Efek Indonesia, 2020 IDX LQ 45 Agustus 2017 - January 2018, di akses 15 Februari 2020

www.idx.co.id. Bursa Efek Indonesia, 2020 IDX LQ 45 February 2018 - July 2018, di akses 15 Februari 2020

www.idx.co.id. Bursa Efek Indonesia, 2020 IDX LQ 45 Agustus 2018 - January 2019, di akses 15 Februari 2020

www.idx.co.id. Bursa Efek Indonesia, 2020 IDX LQ 45 February 2019 - July 2019, di akses 15 Februari 2020

www.idx.co.id. Bursa Efek Indonesia, 2020 IDX LQ 45 Agustus 2019 - January 2020, di akses 15 Februari 2020 